\title{
Historia de las burocracias estatales en Argentina: contribuciones interdisciplinarias
}

\begin{abstract}
Reseña de: Di Liscia, M. S. y Soprano, G. (eds.) (2017). Burocracias estatales. Problemas, enfoques y estudios de caso en la Argentina (entre fines del siglo XIX y XX). Rosario: Prohistoria editorial, y Cesano, J. D. y Grisendi, E. (comps.) (2017). La institución de un orden. Perfiles intelectuales, culturas jurídicas y administración de justicia en Córdoba, 1850 - 1950. Córdoba: Ediciones Lerner SRL.
\end{abstract}

\author{
Milena Luciano \\ Centro de Investigaciones y Estudios sobre Cultura y Sociedad (CIECS), CONICET, \\ Universidad Nacional de Córdoba, Argentina \\ mileluciano@hotmail.com
}

Las compilaciones reunidas en la reseña constituyen aportes historiográficos recientes que problematizan la existencia de lo que podríamos denominar "barreras" disciplinarias en las ciencias sociales, abordando temáticas en donde tradicionalmente predominaron enfoques sociológicos, filosóficos o jurídicos. En este sentido, los trabajos que analizaremos indagan el Estado "desde adentro" (Bohoslavsky y Soprano, 2010, p. 11), pues examinan las burocracias estatales desde sus lógicas internas, prácticas, perfiles de sus agentes, trayectorias profesionales y tensiones con otros ámbitos e instituciones.

El volumen compilado por María Silvia Di Liscia y Germán Soprano comprende una serie de estudios sobre las burocracias en Argentina, desde aquellas especializadas en higiene pública y control migratorio de finales del siglo XIX, hasta los aspectos burocráticos que pueden observarse en las Fuerzas Armadas, durante la transición democrática (1983 - 1990). Aun con la amplia variedad de agencias analizadas, el avance de la presencia del Estado, visibilizado y materializado en sus agentes burocráticos y prácticas, se constituye como un eje transversal presente en cada una de las publicaciones reunidas. En efecto, se logra una mirada integral sobre la formación y despliegue de las burocracias en Argentina, atendiendo a la heterogeneidad del Estado como espacio polifónico en el cual se expresan diferentes grupos e intereses (Bohoslavsky y Soprano, 2010, p. 14).

La concepción de un accionar heterogéneo de las burocracias estatales y problematizadora de los procesos de racionalización burocrática, puede observarse en una primera sección del libro mencionado, mediante el estudio de M. Silvia Di Liscia sobre el accionar del Departamento Nacional de Higiene y la Dirección General de Inmigración. La autora a partir del análisis de los migrantes que fueron aceptados por el organismo, a pesar de no ajustarse a los parámetros establecidos, cuestiona por un lado el poder efectivo y cohesionador del Estado en las tareas de control social -exaltado muchas veces en los discursos oficiales- y, por el otro, confiere un rol activo a los sujetos afectados como actores dotados de estrategias tendientes a superar los controles.

En una segunda sección Stella Maris Cornelis y María José Billorou recuperan, en cada uno de sus artículos, la presencia del Estado nacional en La Pampa durante su etapa territoriana y luego con su provincialización, en un momento de redefinición del rol del Estado. Cornelis brinda un panorama muy diverso y completo de las burocracias y reglamentaciones que organizaron las prácticas de la policía, el Registro de Marcas, salud pública y oficinas destinadas a las políticas educativas. El despliegue de esta última burocracia es trabajada por Billorou, remarcando el accionar de los Inspectores Visitadores como figuras visibles del Estado nacional, 
quienes en su doble función de controlar y orientar las prácticas educativas, tomaron conocimiento de las demandas locales y actuaron como mediadores en la implementación de los lineamientos estatales.

La influencia de las coyunturas políticas y económicas en los procesos de formación y profesionalización de las burocracias estatales se desarrolla en una tercera sección del libro, específicamente en los artículos de Ana Virginia Persello, Carolina Biernat y Karina Ramacciotti y de Osvaldo Graciano. Persello recupera el grado de intervención estatal en lo relativo a política económica a partir del caso de la Comisión de Control de Cambios (1931), organismo caracterizado por la improvisación y precariedad de su sistema de regulación. Estos aspectos fueron recurrentes en una agencia pensada como transitoria hasta finalmente ser absorbida por el Banco Central de la República Argentina.

El peso de las coyunturas políticas también se expresa en la profesionalización de la burocracia sanitaria examinada por Biernat y Ramacciotti. Allí cobraron especial relevancia, además de la formación académica universitaria especializada en Salud Pública, las vinculaciones político-partidarias de los agentes como requisito de ingreso y permanencia en el cargo; esto en un contexto político signado por sus constantes vaivenes (1950-1960). De esta manera, la titulación habría cumplido una función legitimadora de cargos ya designados.

La centralidad del ámbito universitario y sus discursos se observa en la investigación de Graciano sobre la valorización de la genética vegetal como respuesta frente al estancamiento de la agricultura pampeana entre las décadas de 1920 y 1930 . No obstante, la connotación política es señalada por Graciano ya que, según el autor, existían otras alternativas ante la crisis que posiblemente habrían significado reformas políticas más profundas que afectasen a la propiedad de la tierra, comercialización e inversiones extranjeras. Esta vinculación entre el Estado nacional y el sistema universitario propició la formación de complejos de investigación en genética vegetal en las facultades de agronomía de Buenos Aires y de La Plata.

En la última sección, el trabajo de Germán Soprano cierra una serie de contribuciones para pensar y estudiar las burocracias, reflexionando sobre las potencialidades de la conceptualización de Burocracia Moderna de Max Weber para explicar las lógicas que guiaron las prácticas de las Fuerzas Armadas (FFAA) en la transición democrática. Los principales aportes del artículo son, en primer lugar, la problematización del rol político tradicionalmente otorgado por las ciencias sociales a las FFAA en Argentina para comprender sus dinámicas y, en segundo término y muy relacionado con lo anterior, se rescatan aquellas particularidades de la burocracia militar por las cuales no es posible equipararla con otras burocracias estatales.

Por su parte, la compilación realizada por Jose D. Cesano y Ezequiel Grisendi, reconstruye las dinámicas institucionales y los perfiles intelectuales de las burocracias abocadas a la administración de la justicia en Córdoba, intentando contextualizar los procesos sociales que comprenden a los diferentes entramados jurídicos (Cesano y Grisendi, 2017, p. 14). En consonancia con aportes historiográficos recientes sobre la injerencia del Estado nacional en las agencias provinciales (Palermo y Silva, 2016, p. 8), los trabajos ponen en diálogo las dinámicas nacionales con las trayectorias institucionales y académicas provinciales. A su vez, los artículos del segundo volumen reseñado constituyen aportes para una historia crítica del derecho que, lejos de quedarse en los antagonismos disciplinarios tradicionales entre historia social e historia del derecho (Barreneche, 2015, p. 9), atienden a la multidimensionalidad de las instituciones judiciales.

En una primera sección, Liliana Chaves y Agostina Gentili -en diferentes periodos- abordan procesos de burocratización del Poder Judicial de Córdoba. Para explicar la racionalización institucional atravesada por la Justicia de Córdoba entre 1853 y 1887, Chaves relaciona cuatro dimensiones: el accionar de las elites políticas dirigentes, los cambios institucionales, académicos y el proceso de codificación penal. De este modo, la conformación del Poder Judicial como burocracia demandó profesionales y, en consecuencia, generó disputas en torno a las instancias de titulación y criterios de selección, en donde las estrategias de las elites dirigentes locales tuvieron una gran importancia a la hora de permitir u obstaculizar ciertos ingresos. Este último aspecto resulta fundamental para comprender el rol legitimador del orden jurídico y social que poseen los tribunales (Coterrell, 1991, p. 207). 
El Poder Judicial de Córdoba también es analizado por Gentili, mediante la reconstrucción de las representaciones sobre la infancia y juventud "abandonada y delincuente", previas a la creación de un fuero específico para menores en 1957. Gentili atiende a las trayectorias recorridas a nivel nacional sobre procedimientos judiciales para menores, destacando periodos de confluencia y distancias con respecto a las dinámicas provinciales. En este proceso puede evidenciarse una progresiva penetración del Poder Ejecutivo provincial en un área que había sido gestionada tradicionalmente por instituciones particulares.

En una segunda y última sección, María Belén Portelli investiga un periodo en dónde el saber experto fue valorado por las elites dirigentes locales como medio para enfrentar problemáticas sociales, en este caso, como diagnóstico para elaborar respuestas frente a la emergencia de la conflictividad obrera de comienzos del siglo XX. A partir del análisis de la figura del letrado especialista en derecho laboral, Dardo Rietti, entre 1906 y 1943, Portelli explica los cambios producidos en la enseñanza del Derecho Laboral en la Universidad Nacional de Córdoba, desde la transmisión de saberes enciclopédicos hacia una enseñanza práctica, muy influenciada por la Reforma Universitaria de 1918.

Tanto la compilación de Di Liscia y Soprano, como la realizada por Cesano y Grisendi, desde escalas diferentes, reflejan los cambios producidos en la historiografía de los últimos años, signados por la ampliación de las temáticas trabajadas que demandaron perspectivas más complejas y, en consecuencia, diálogos interdisciplinarios más fluidos (Caimari, 2016, p. 8). En este sentido, pensar que ciertos objetos de estudio deben ser indagados por determinadas disciplinas según su especificidad, no solo resultaría un anacronismo, sino que también nos conduciría a construir explicaciones parciales.

Atentos a lo anterior, los trabajos reseñados son el resultado de minuciosas indagaciones de una gran variedad de fuentes que iluminan la divergencia de casos, de modos de acción y la penetración del Estado en diferentes ámbitos, territorios y niveles, cuestionando carácter uniforme y homogenizador otorgado por las interpretaciones tradicionales al Estado.

Ambas compilaciones también recuperan la dinámica coyuntural en la formación de las burocracias, situándolas en contextos políticos y económicos cambiantes que en algunas ocasiones son receptivos a los saberes expertos con miras a la profesionalización de los funcionarios estatales y, en otros, confieren mayor peso a otros factores como, por ejemplo, lo político partidario.

Para cerrar, consideramos que las perspectivas que se desarrollan en los volúmenes reseñados logran recuperar los aspectos subjetivos de las burocracias estatales, es decir, valores, emociones y elecciones no racionales que subyacen en los procesos de racionalización burocráticos (Garland, 2006, p. 223), presentándolas como instituciones compuestas por agentes que al ejecutar las normativas le otorgan materialidad a las prácticas y las modelan. El reconocimiento e identificación de estas dinámicas sin duda constituye un punto de partida central para futuras indagaciones.

\section{Bibliografía}

Barreneche, O. (2015). Las instituciones de seguridad y del castigo en Argentina y América Latina. Recorrido historiográfico, desafíos y propuestas de diálogo con la historia del derecho. Revista de Historia de las Prisiones, 1, 5-33. Recuperado de: http://www.revistadeprisiones.com/wp-content/uploads/2016/08/1_Barreneche.pdf

Bohoslavsky, E. y Soprano, G. (eds.) (2010). Un Estado con rostro humano. Funcionarios e instituciones estatales en Argentina (desde 1880 hasta la actualidad). Buenos Aires: Prometeo - UNGS.

Caimari, L. (2016). Los historiadores y la "cuestión criminal" en América Latina. Notas para un estado de la cuestión. Revista de Historia de las Prisiones, 2, 5-15. Recuperado de: http://www.revistadeprisiones.com/wp-content/u ploads/2016/06/1_Caimari.pdf

Coterrell, R. (1991). Introducción a la sociología del derecho. Barcelona: Ariel Derecho.

Garland, D. (2006). Castigo y sociedad moderna. Un estudio de teoria social. México: Siglo XXI. 
Sociohistórica, n 43 , e078, marzo-agosto 2019. ISSN 1852-1606

Palermo, S. y Silva J. (2016). Expertos, burocracias y política de masas en Argentina. Estudios Sociales del Estado, 2(3), 6-21. 